\title{
Serological Properties of the Wall and Membrane Teichoic Acids from Lactobacillus helveticus NCIB 8025
}

\author{
By K. W. KNOX \\ The Institute of Dental Research, United Dental Hospital, \\ Surry Hills, New South Wales, Australia 2010 \\ AND A. J. WICKEN \\ School of Microbiology, University of New South Wales, \\ P.O. Box I, Kensington, New South Wales, Australia 2033 \\ (Accepted for publication 29 July 1970) \\ SUMMARY
}

\begin{abstract}
Both wall and membrane teichoic acids from Lactobacillus helveticus NCIB 8025 are glycerol phosphate polymers partially substituted with $\alpha$-Dglucosyl residues. The membrane teichoic acid, isolated as a complex with lipid (lipoteichoic acid), was antigenic when injected into rabbits with Freund's adjuvant. The $\alpha$-D-glucosyl substituents are primarily responsible for the serological specificity of the membrane antigen, and account for the reaction of wall teichoic acid with antisera to the membrane teichoic acid. Glycerol teichoic acids either differing in or lacking sugar substitution may cross-react and the significance of these observations is discussed.
\end{abstract}

\section{INTRODUCTION}

The serological classification of micro-organisms may be based on the agglutination of whole organisms or the reactivity of solubilized cell components with specific antisera. Both procedures have been utilized in the serological classification of the lactobacilli. The work of Sharpe (I955) showed that most strains of lactobacilli can be divided into one of six serological groups on the basis of the reaction of Lancefield acid extracts with antisera prepared against whole organisms. Subsequently, Sharpe, Davison \& Baddiley (1964) concluded that the group A antigen (Lactobacillus helveticus-jugurti group) was an intracellular (membrane) glycerol teichoic acid. Mills (1969) has recently studied the agglutinating antigens of $L$. jugurti and concluded that the cell-wall teichoic acid is the major antigen in the cell wall of group A lactobacilli, while the intracellular teichoic acid was also serologically active.

This study reports more definitive investigations into the chemical structure and serological properties of the wall and membrane (intracellular) teichoic acids. The reaction of these teichoic acids with antisera against other lactobacilli and group A streptococci has also been investigated.

\section{METHODS}

Organisms. Strains of lactobacilli were obtained originally from the National Collection of Type Cultures, Colindale, London, or from Dr M. E. Sharpe, National Institute for Research in Dairying, Reading, Berkshire, and were representative of 
each of the serological groups: Lactobacillus helveticus NCIB8025 (group A), L. casei NIRDH83I (group B), L. casei NIRD R094 (group C), L. plantarum NCIB 7220 (group D), L. lactis NCIB 7228 (group E), and L. fermenti NCTC699I (group F). A strain of group A streptococcus was isolated and identified by $\mathrm{Mr} \mathrm{H}$. C. Spies of this Institute. Organisms were grown for $18 \mathrm{~h}$. at $37^{\circ}$, lactobacilli in the medium described by Sharpe et al. (1964), and streptococci in Todd-Hewitt broth.

Preparation of teichoic acid. Suspensions of washed Lactobacillus helveticus were disrupted with Ballotini beads (no. 13) and cell walls isolated and washed by the method described previously (Knox \& Hall, 1965). Teichoic acid was extracted from these cell walls by two procedures: (i) Walls were extracted conventionally with cold $10 \%$ trichloracetic acid (TCA) for $48 \mathrm{~h}$., crude teichoic acid being recovered from the clarified supernatant of centrifuged extracts by precipitation with $5 \mathrm{vol}$. of $96 \%$ ethanol. (ii) Suspensions of cell walls in $0.5 \mathrm{~N}-\mathrm{NaOH}$ were stirred at room temperature for $4 \mathrm{~h}$. (Archibald, Coapes \& Stafford, I969), and after centrifugation the clear supernatant fluid was neutralized with $\mathrm{HCl}$ and then dialysed. Crude teichoic acid was recovered by freeze-drying. Teichoic acid preparations from both (i) and (ii) were purified further by chromatography in $0.2 \mathrm{M}$-ammonium acetate, $\mathrm{pH} 6 \cdot 9$, on columns of Sephadex G 75 (Wicken \& Knox, 1970).

The nonsedimentable material obtained after centrifuging disintegrated organisms (I2,000 $\mathrm{g}, 20 \mathrm{~min}$., Serval $\mathrm{RC}_{2}$ centrifuge) was used as the source of membrane teichoic acid. Teichoic acid was extracted with cold aqueous phenol and purified by chromatography in $0.2 \mathrm{M}$-ammonium acetate on columns of $6 \%$ agarose (Litex, Denmark) as described previously (Wicken \& Knox, 1970).

Dr M. McCarty kindly provided a sample of polyglycerophosphate (glycerol teichoic acid) prepared from a group A streptococcus strain D58 (type 3) (McCarty, 1959).

Preparation of antisera. Group-specific antisera were prepared by the intravenous injection of suspensions of bacteria (Sharpe, I955; Knox, Hewett \& Wicken, 1970). The antigenicity of the membrane teichoic acid from Lactobacillus helveticus was examined by injecting subcutaneously an emulsion containing equal volumes of teichoic acid solution and Freund's complete adjuvant (Knox, Hewett \& Wicken, 1970).

Serological methods. The specificity of group antisera was examined initially by the qualitative ring precipitin method (Sharpe, 1955). Quantitative precipitin reactions and haemagglutination titres were determined by the methods previously used with Lactobacillus fermenti (Hewett, Knox \& Wicken, 1970; Knox et al. 1970).

Analytical methods. Conditions for the acidic and alkaline hydrolysis of teichoic acids, enzymic dephosphorylation, characterization of glycosides and identification of products by paper chromatography, unless stated in the text, are essentially as described previously (Forrester \& Wicken, I966; Wicken, 1966). Procedures for quantitative analyses have been detailed by Wicken \& Knox (1970).

Paper chromatography. The following solvent systems were used for paper chromatography: (a) propan-r-ol+aq. ammonia (sp.gr. $0 \cdot 88)+$ water $(6+3+\mathrm{r}$, by vol.; Hanes \& Isherwood, I949), Whatman paper no. 4, ascending; (b) butan-I-ol + pyridine+ water $(6+4+3$, by vol.; Jeanes, Wise \& Dimler, 195I), Whatman paper no. I or $3 \mathrm{MM}$, descending; $(c)$ ethyl acetate + pyridine + water $(5+2+5$, by vol., upper layer; Sastry \& Kates, 1964), Whatman paper no. I or 3 MM, descending. Chromatographic spray reagents were as detailed previously (Wicken \& Knox, I970). 


\section{RESULTS}

\section{Teichoic acids of Lactobacillus helveticus}

Wall teichoic acid was obtained in yields of $13.6 \%$ and $9.1 \%$ of the dry weight of cell walls by TCA and sodium hydroxide extraction respectively, after chromatography on Sephadex G $75\left(K_{\mathrm{d}} c a .0 .5\right)$. Paper chromatography of acid hydrolysates of both preparations showed products typical of glycerol teichoic acids substituted with glucose and, in the case of TCA-extracted teichoic acid, D-alanyl esters. Quantitative estimation of $\mathrm{D}$-glucose and phosphorus in acid hydrolysates gave mole ratios of $0 \cdot 64: 1 \cdot 00$ and $0.56: 1 \cdot 00$ respectively for TCA- and sodium hydroxide-extracted teichoic acids. These values compared favourably with the glucose: phosphorus mole ratio of $0 \cdot 6 \mathrm{r}: \mathrm{r} \cdot 00$ for whole cell walls. Isolated cell walls contained $\mathrm{I} \cdot 37 \mu$ moles phosphorus/mg. dry weight which is indicative of a total teichoic acid content of about $35 \%$ by weight, assuming that all of the phosphorus in the cell wall is accounted for by teichoic acid; this would represent approximately $7 \%$ of the total cell mass.

Phenol-extracted membrane teichoic acid was eluted, free of nucleic acid material, close to the void volume from $6 \%$ agarose columns, and appeared to be of the same order of molecular size as the P- or lipoteichoic acid isolated from Lactobacillus fermenti NCTC699I (Wicken \& Knox, 1970); the yield from 21 g. dry weight of organisms was $96 \mathrm{mg}$., or approximately $0.5 \%$ of the total cell mass. Acid hydrolysates of this material showed, in addition to the components found in wall teichoic acid, fatty acid(s) and traces of galactose as well as associated protein material. Quantitative analyses gave $4.4 \%$ fatty acid esters (as palmitic acid) and the mole ratio of glucose: galactose:phosphorus was $0 \cdot 45: 0 \cdot 025: \mathrm{I} \cdot 00$.

Alkaline phosphomonoesterase treatment of alkali-hydrolysed wall teichoic acid gave glycerol, traces of diglycerol monophosphate, a small amount of a glycoside, traces of an organic phosphate ester, and appreciable quantities of a material containing organic phosphate. The latter migrated as a broad band $\left(R_{\text {glycerol }}=0.0\right.$ to 0.18$)$ in solvent A and had a glucose: phosphorus ratio of I $\cdot 09$ : I. Diglycerol monophosphate was identified by its mobility in solvent $A$ and rapid reaction with the periodate + Schiff's reagent on paper chromatograms. The glycoside gave a slow reaction with the periodate + Schiff's reagent, characteristic of a 2-substituted glycerol, and after acid hydrolysis showed D-glucose and glycerol as the only constitutents in the mole ratio of $0.93: 1 \cdot 00$. It was not hydrolysed by $\beta$-glucosidase and was chromatographically indistinguishable from authentic 2-0- $\alpha$-D-glucopyranosyl-glycerol, having $R_{\text {glucose }}$ values of $\mathrm{I} \cdot 10$ and $\mathrm{I} \cdot 03$ in solvents $\mathrm{B}$ and $\mathrm{C}$ respectively. Hydrolysis of wall teichoic acid in $60 \% \mathrm{HF}$ at $0^{\circ}$ (Glaser \& Burger, 1964) followed by treatment with phosphomonoesterase gave a good yield of this glycoside as well as glycerol, and no evidence of higher glycosidic substitution of glycerol was obtained. These results are consistent with 2-0- $\alpha$-D-glucosyl-substitution of many of the glycerol moieties in these teichoic acid preparations. The phosphate ester $\left(R_{p}=0.43\right.$ in solvent $\left.\mathrm{A}\right)$ obtained from alkaline + enzymic hydrolysis was unchanged by further treatment with these agents, and gave a slow reaction with the periodate + Schiff's reagent analogous to that given by the glycoside above. Acid hydrolysis gave glycerol, glucose and glycerol monophosphates. The ester is therefore likely to be diglucosyldiglycerol monophosphate which has an identical reported $R_{r}$ in solvent A (Shaw \& Baddiley, 1964).

Degradation of membrane teichoic acid by alkali and phosphomonoesterase or by 
$60 \% \mathrm{HF}$ gave products essentially similar to those from wall teichoic acid. In addition, hydrolysis by alkali yielded a small quantity of a glycoside containing glucose and galactose $\left(R_{\text {glocose }}=0.3 \mathrm{I}\right.$ in solvent $\left.\mathrm{B}\right)$ and reacting rapidly with the periodate+ Schiff's reagent. The monoglucosylglycoside was chromatographically identical to that obtained from wall teichoic acid and similarly was not hydrolysed by $\beta$-glucosidase.

\section{Reaction of teichoic acids from Lactobacillus helveticus with homologous antisera}

\section{Reactivity of antisera to Lactobacillus helveticus cells}

Antisera obtained from three rabbits injected with a suspension of Lactobacillus helveticus gave a positive reaction in the qualitative ring precipitin test with an acid extract of the organisms. When examined by the quantitative precipitin method the most active serum (rabbit $\mathrm{I}_{59}$ ) contained, per ml., only $0.23 \mathrm{mg}$. of antibody reacting with membrane teichoic acid and $<0.1 \mathrm{mg}$. reacting with wall teichoic acid.

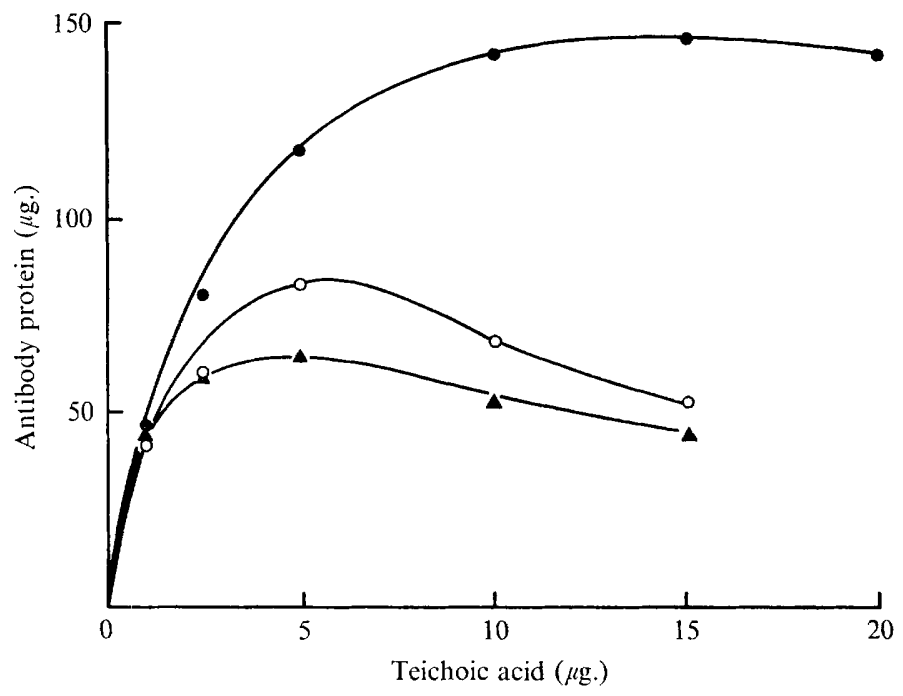

Fig. I. Precipitation of teichoic acids from Lactobacillus helveticus by antiserum $(0.1 \mathrm{ml}$.) against membrane teichoic acid (rabbit 176);, Membrane teichoic acid; $\bigcirc$, ammoniadegraded membrane teichoic acid; $\boldsymbol{\Delta}$, wall teichoic acid.

\section{Reactivity of antisera to membrane teichoic acid}

Antisera prepared against the isolated membrane teichoic acid reacted with both the wall and membrane teichoic acids; with membrane teichoic acid the amount of antibody in sera from rabbits 175,176 and $\mathrm{I} 77$ was estimated to be $\mathrm{I} \cdot 2, \mathrm{I} \cdot 5$ and $0.8 \mathrm{mg} . / \mathrm{ml}$. respectively. The reactions of the wall and membrane teichoic acids with antiserum I 76 (O. I ml.) are compared in Fig. I. The weaker reaction of wall teichoic acid could be related to its molecular weight being considerably less than that for the membrane teichoic acid. It was shown previously (Knox et al. 1970) that aqueous ammonia degraded high molecular weight membrane teichoic acid from Lactobacillus fermenti, removing fatty acids and yielding a product with serological properties similar to those of low molecular weight teichoic acid. Treatment of a solution of L. helveticus mem- 
brane teichoic acid with an equal volume of aqueous ammonia (sp.gr. 0.88) at room temperature for $\mathrm{I} 6 \mathrm{~h}$. decreased its serological reactivity, the quantitative precipitin curve now being similar to that for the wall teichoic acid (Fig. r).

In earlier studies on teichoic acid preparations from Lactobacillus fermenti (Hewett et al. 1970), the application of the haemagglutination procedure indicated that lipoteichoic acids adsorbed to sheep erythrocytes whereas lipid-free teichoic acid did not. Similar studies with $L$. helveticus preparations have shown that the membrane lipoteichoic acid but not the wall teichoic acid sensitizes sheep erythrocytes. The titre of antiserum 176 using these sensitized erythrocytes was 800; prior absorption of antiserum with whole organisms (Hewett et al. 1970) decreased the titre to 200.

\title{
Table I. Inhibition of precipitin reaction between teichoic acids and antisera prepared against membrane teichoic acid from Lactobacillus helveticus
}

\begin{abstract}
The antisera were examined for serological specificity using membrane teichoic acid, ammonia-degraded membrane teichoic acid and wall teichoic acid prepared from $L$. helveticus. Results are recorded in the form of percentage inhibition of the precipitin reaction when glucose, methyl- $\alpha$-D-glucoside or methyl- $\beta$-D-glucoside was present.
\end{abstract}

$\begin{array}{clccc}\begin{array}{c}\text { Antiserum } \\ \text { from } \\ \text { rabbit }\end{array} & \text { Teichoic acid } & \text { Glucose } & \begin{array}{c}\text { Methyl- } \alpha-\mathrm{D} \\ \text { glucoside }\end{array} & \begin{array}{c}\text { Methyl- } \beta \text {-D } \\ \text { glucoside }\end{array} \\ 175 & \text { Membrane } & 38 & 52 & 18 \\ 177 & \text { Membrane } & 25 & 51 & 13 \\ 176 & \text { Membrane } & 35 & 47 & 20 \\ & \text { Degraded membrane } & 44 & 59 & 22 \\ & \text { Wall } & 42 & 61 & 25\end{array}$

\section{Specificity of antisera to membrane teichoic acid}

D-Glucose, methyl- $\alpha$-D-glucoside and methyl- $\beta$-D-glucoside were examined for their ability to inhibit the precipitin reaction between membrane teichoic acid (Io $\mu \mathrm{g}$.) and each of the antisera $175(0.1 \mathrm{ml}$.), I76 (0.I ml.) and I $77(0.2 \mathrm{ml}$.). The detailed results for antiserum 176 are given in Fig. 2 while Table $I$ compares the degree of inhibition by $20 \mu$ moles of carbohydrate for each of the sera. The results indicate that $\alpha-D-$ glucosyl substituents were primarily responsible for the reaction between membrane teichoic acid and the antisera.

D-Glucose, methyl- $\alpha$-D-glucoside and methyl- $\beta$-D-glucoside were also compared as inhibitors of the precipitin reactions between antiserum $176(0.2 \mathrm{ml}$.) and both wall teichoic acid $(5 \mu \mathrm{g}$.) and ammonia-degraded membrane teichoic acid (ro $\mu \mathrm{g}$.). The results for $20 \mu$ moles of carbohydrate are included in Table $I$ and the detailed results for wall teichoic acid are given in Fig. 3. The results with degraded membrane teichoic acid indicate that it retained its serological specificity. The results with wall teichoic acid indicate that this preparation cross-reacted with antiserum to membrane teichoic acid because of the presence of $\alpha$-D-glucosyl substituents. Figure 3 also shows that galactose partially inhibited this precipitin reaction although galactose is not a substituent of either the wall teichoic acid or the polyglycerophosphate component of the membrane teichoic acid. 


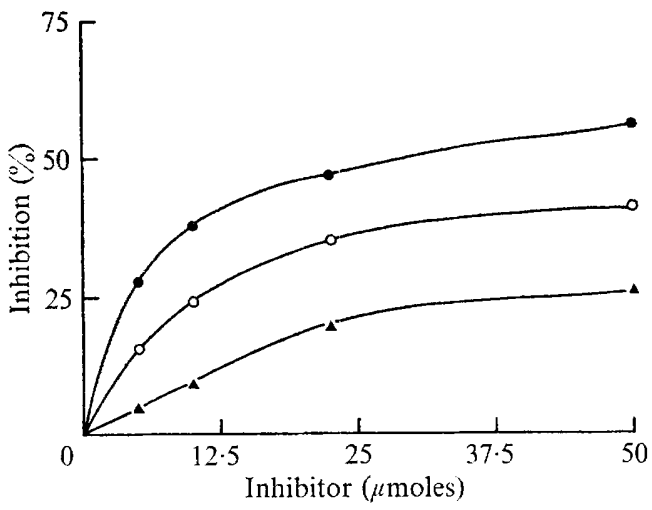

Fig. 2

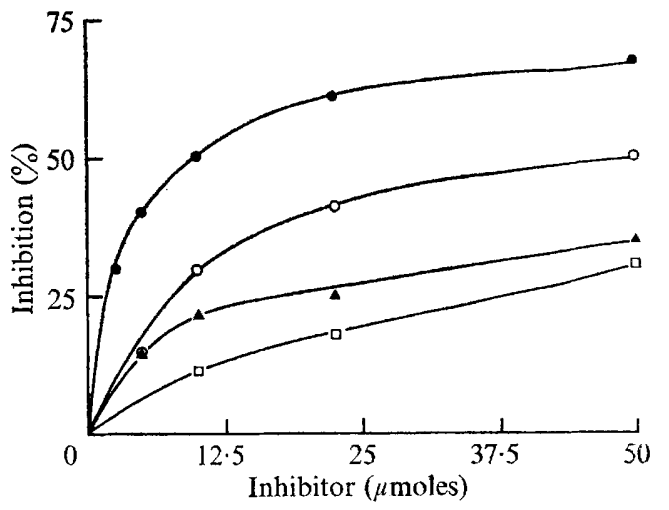

Fig. 3

Fig. 2. Inhibition of the precipitin reaction between membrane teichoic acid (10 $\mu$ g.) and homologous antiserum (rabbit $176,0 \cdot 1 \mathrm{ml}$.) by $\mathrm{D}$-glucose $(O)$, methyl- $\alpha$-D-glucoside $(O)$ and methyl- $\beta$-D-glucoside (A).

Fig. 3. Inhibition of precipitin reaction between wall teichoic acid $(5 \mu \mathrm{g}$.) and antiserum $\mathrm{I} 76$ $(0.2 \mathrm{ml}$.) by D-glucose (O), methyl- $\alpha-\mathrm{D}$-glucoside (O), methyl- $\beta-\mathrm{D}$-glucoside (A) and galactose $(\square)$.

\section{Serological cross-reactions between teichoic acids from different bacterial species}

Reaction of antisera to Lactobacillus helveticus teichoic acid with other teichoic acids

The results of the chemical and serological experiments described above indicate that both the cell wall and membrane teichoic acids of Lactobacillus helveticus are glycerophosphate polymers partially substituted with $\alpha$-D-glucosyl residues. Antiserum against membrane teichoic acid (rabbit 176) was next tested for its reaction with polyglycerophosphate from group A streptococci (McCarty, 1959), and membrane teichoic acid from $L$. fermenti NCTC699I; the latter preparation, designated P-teichoic acid (Wicken \& Knox, 1970), contained glucose and galactose substituents. The cross-reactions were determined by the quantitative precipitin method, the maximum amount of antibody precipitated being expressed as a percentage of the maximum precipitated in the homologous reaction. The results (Table 2) showed that there was a moderate degree of cross-reaction between $L$. fermenti teichoic acid and antiserum 176 whereas streptococcal polyglycerophosphate reacted very weakly.

The cross-reaction with Lactobacillus fermenti teichoic acid was also examined by the haemagglutination procedure using sheep erythrocytes sensitized with this teichoic acid preparation; the titre with antiserum 176 was 200 compared with 800 for the homologous reaction using sheep erythrocytes sensitized with $L$. helveticus membrane teichoic acid.

\section{Reaction of teichoic acids with antisera to group $A$ streptococci}

Each of the three rabbits ( $170,171,172)$ injected with group A streptococci gave antisera which reacted strongly in the qualitative ring precipitin test with streptococcal polyglycerophosphate (100 $\mu \mathrm{g} . / \mathrm{ml}$.). All quantitative tests were carried out with antiserum 170 . This antiserum reacted strongly with Lactobacillus fermenti and $L$. helveticus membrane teichoic acids (Fig. 4) and moderately with L. helveticus wall teichoic acid 
(Table 2). Using sheep erythrocytes sensitized with $L$. helveticus membrane teichoic acid, the haemagglutination titre of antiserum 170 was $I 600$. These results showed that whereas streptococcal polyglycerophosphate reacted very weakly with antiserum specific for $\alpha$-D-glucosyl substituents (rabbit I76), teichoic acids from $L$. helveticus reacted well with antisera to group A streptococci (rabbit 170). The reaction of L. helveticus membrane teichoic acid with antiserum 170 was not inhibited by IOO $\mu$ moles of D-glucose, suggesting that the cross-reaction was dependent on the polyglycerophosphate component of the membrane teichoic acid rather than due to the presence of an unknown $\alpha$-glucosyl-specific antigen in the streptococci.

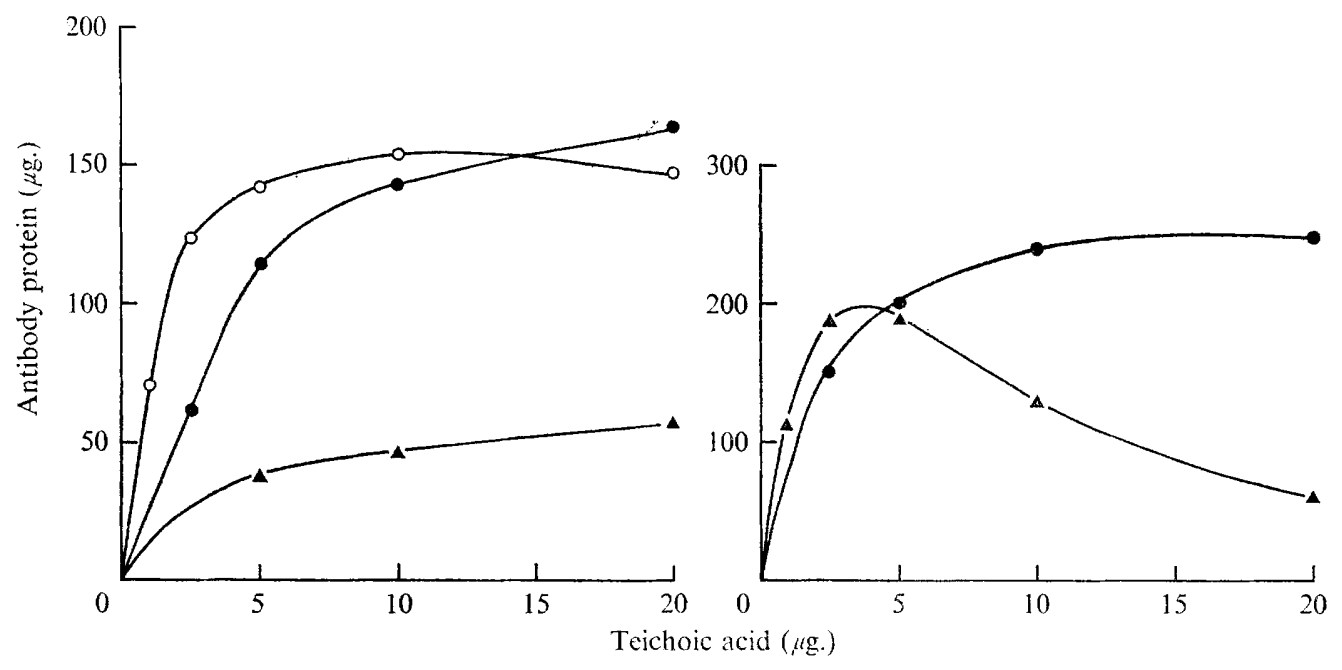

Fig. 4

Fig. 5

Fig. 4. Precipitation of teichoic acids by antiserum ( $0.3 \mathrm{ml}$.) against group A streptococci (rabbit I70). O, Streptococcal polyglycerophosphate; 0 , membrane teichoic acid and, $\boldsymbol{\Delta}$, wall teichoic acid from Lactobacillus helveticus.

Fig. 5. Precipitation of teichoic acids from Lactobacillus helveticus by antiserum (O. I ml.) against $L$. plantarum (rabbit I64). - Membrane teichoic acid; $\Delta$, wall teichoic acid.

Table 2. Cross-reactions of antisera with preparations of teichoic acid

Values are expressed as a percentage of the amount of antibody precipitated in the homologous reaction.

Source of teichoic acid

Preparation injected

Lactobacillus helveticus membrane teichoic acid Group A streptococcus L. fermenti membrane teichoic acid

\begin{tabular}{|c|c|c|c|c|}
\hline \multirow[b]{2}{*}{$\begin{array}{l}\text { Antiserum } \\
\text { from } \\
\text { rabbit }\end{array}$} & \multicolumn{4}{|c|}{ Source of teichoic acid } \\
\hline & $\begin{array}{c}\text { Group A } \\
\text { strepto- } \\
\text { coccus }\end{array}$ & $\begin{array}{c}L . \\
\text { fermenti } \\
\text { membrane }\end{array}$ & $\begin{array}{c}L . \\
\text { helveticus } \\
\text { membrane }\end{array}$ & $\begin{array}{c}L . \\
\text { helveticus } \\
\text { wall }\end{array}$ \\
\hline 176 & 5 & 30 & 100 & 38 \\
\hline 170 & 100 & 102 & 105 & 28 \\
\hline 146 & $32^{*}$ & 100 & 72 & 32 \\
\hline I 49 & $32 *$ & 100 & 73 & $2 I$ \\
\hline I 47 & $15^{*}$ & 100 & 38 & 17 \\
\hline I 48 & $25^{*}$ & 100 & 40 & I6 \\
\hline
\end{tabular}

* From Knox, Hewett \& Wicken, 1970. 
To confirm that the cross-reaction depended on antibodies against the streptococcal glycerol teichoic acid, antiserum I70 $(0.75 \mathrm{ml}$.) was mixed with streptococcal polyglycerophosphate $(25 \mathrm{ug} . / 0 \cdot 25 \mathrm{ml}$.), the resultant precipitate removed, and the supernatant solution ( $0.4 \mathrm{ml}$.) tested for its reaction with Lactobacillus helveticus membrane teichoic acid $(20 \mu \mathrm{g}$.). The amount of precipitate that formed on standing was $<10 \%$ of that formed in the control experiment omitting polyglycerophosphate.

In a similar experiment absorption of antiserum 170 ( 10 ml.) with Lactobacillus fermenti P-teichoic acid (I mg.) decreased the reactivity of the antiserum with streptococcal polyglycerophosphate by $80 \%$, and the reaction with $L$. helveticus membrane teichoic acid by $90 \%$. The precipitate that had formed on the addition of the L. fermenti teichoic acid was analysed to confirm the presence of glucose and galactose: relative to the amount of teichoic acid added, the recoveries of phosphorus, glucose and galactose were $75 \%, 63 \%$ and $67 \%$ respectively.

\section{Reaction of teichoic acids with antisera to Lactobacillus fermenti}

Antisera prepared against Lactobacillus fermenti membrane teichoic acid were examined for their reaction with $L$. helveticus teichoic acids; their reaction with the streptococcal polyglycerophosphate has already been described (Knox et al. 1970). The sera chosen illustrated the differences in specificity which were observed, and the values in brackets indicate the percentage inhibition of the homologous reaction by I00 $\mu$ moles of glucose and galactose respectively (Knox et al. 1970): antiserum I46 $(6 \%$, I0 \%), I $49(4 \%$, I I \%), I $47(7 \%, 36 \%)$ and $\mathrm{I} 48(22 \%, 44 \%)$. The cross-reactions with the $L$. helveticus teichoic acids (Table 2) reflect the specificities of the antisera, with 147 and 148 cross-reacting less than 146 and I 49.

The cross-reactions were also detected by the haemagglutination procedure: the titre of antiserum 146 was 1600 when tested with erythrocytes sensitized with Lactobacillus fermenti P-teichoic acid and 800 when tested with $L$. helveticus membrane teichoic acid, whilst for antiserum I48 the respective titres were 3200 and 1600 .

\section{Reaction of Lactobacillus helveticus teichoic acids with antisera to other lactobacilli}

By using the qualitative ring precipitin test Lactobacillus helveticus membrane teichoic acid (100 $\mu \mathrm{g} . / \mathrm{ml}$ ) was shown to react well with antisera against groups D and $\mathrm{E}$ lactobacilli, but not with antisera against groups $\mathrm{B}$ and $\mathrm{C}$ lactobacilli. The quantitative reactions of $L$. helveticus membrane and wall teichoic acids with group D antiserum (0.1 ml. from rabbit $\left.{ }^{164}\right)$ are compared in Fig. 5. The amount of antibody precipitated by the membrane teichoic acid was approximately the same as that precipitated by an impure preparation of membrane teichoic acid from the group $D$ strain, L. plantarum NCIB 7220 (Wicken \& Knox, unpublished observations).

A comparison of the results for Lactobacillus helveticus wall and membrane teichoic acids in Table 2 and Fig. I, 4 and 5 shows that the wall teichoic acid reacted strongly with only group D antisera, where it precipitated $84 \%$ of the amount of antibody precipitated by membrane teichoic acid. Ammonia-degraded membrane teichoic acid also reacted better with group D antiserum, giving $75 \%$ of the reaction of undegraded material compared with $54 \%$ for the reaction with antiserum 176 (Fig. I). 


\section{DISCUSSION}

Sharpe et al. (1964) indicated that the wall and membrane (intracellular) teichoic acids of Lactobacillus helveticus NCIB 8025 were of the glycerol type but only the membrane teichoic acid was appreciably substituted with glucose, a glucosylglycerol being isolated after alkaline hydrolysis of the latter.

The teichoic acid which we isolated from Lactobacillus helveticus NCIB8025 cell walls by either TCA- or sodium hydroxide-extraction contained appreciable quantities of glucose. The glucose:phosphorus mole ratios of these preparations reflected that of unextracted cell walls and suggested that no enrichment of a glucosylated teichoic acid had taken place during extraction. The products of alkali and hydrofluoric acid degradation of wall teichoic acid were consistent with a structure having the normal arrangement of phosphodiester groups between positions I and 3 of each glycerol moiety, and with many of the latter residues being substituted on the secondary hydroxyl group with $\alpha$-D-glucose. The enrichment of glucose in teichoic acid fragments apparently stable to alkali hydrolysis leads us to suggest either regions of full and partial glycosidic substitution within the same polymer chain or a mixture of fully and partially substituted chains: no glucosylglycerol or diglucosyldiglycerol monophosphate could be expected from alkaline and enzymic degradation of a mixture of fully glucosylated and unsubstituted polymers. In this connection it is interesting to note that the wall teichoic acid from $L$. buchneri has been shown to be partially substituted with glucose and has regions of the polymer where adjacent glycerol residues bear glucose substituents (Archibald, Baddiley \& Heptinstall, I969).

The membrane teichoic acid from Lactobacillus helveticus has a lower degree of $\alpha$-glucosyl substitution than the wall polymer. The product isolated by phenol extraction resembled the lipo- or P-teichoic acid of $L$. fermenti NCTC699I, being of high apparent molecular weight and containing a glycolipid component. Evidence for a glycolipid being present was provided by the detection of fatty-acid ester residues and of a glycoside containing glucose and galactose and assumed to be a I-substituted glycerol from its rapid reaction with the periodate + Schiff's reagent. The small amount of the glycoside in alkaline hydrolysates probably reflects the low galactose content of the polymer.

The studies by Sharpe et al. (1964) on the teichoic acids of group A lactobacilli (including Lactobacillus helveticus NCIB 8025) led them to conclude that the membrane teichoic acid was the group antigen, the preparations of wall teichoic acid being serologically inactive when examined by the precipitin reaction. More recently, Mills (I969) studied the agglutinating antigens of a strain of $L$. jugurti of serological group A and concluded that glycerol teichoic acid, containing 'variable traces of glucose', was the major wall component responsible for the agglutination of whole organisms by homologous antisera. Preparations of wall and membrane teichoic acids appeared to be immunologically identical, as determined by the Ouchterlony method, but it was considered unlikely that the membrane teichoic acid component of intact organisms would react with antibodies. Studies on the group F antigen of lactobacilli have indicated that antibody can react with the membrane teichoic acid in situ (Hewett et al. 1970).

The present studies have shown that antibodies prepared against membrane teichoic acid from Lactobacillus helveticus $\mathrm{NCIB} 8025$ reacted with wall teichoic acid because of 
the presence of the $\alpha$-D-glucosyl substituents on the polyglycerophosphate component of both wall and membrane teichoic acid. In terms of the reactivity of Lancefield acid extracts of $L$. helveticus (Sharpe, 1955) or the agglutinability of this organism (Mills, 1969), it is to be expected that the wall teichoic acid would be the major contributor to the serological reaction because of the greater amount of teichoic acid in the wall. However, none of the studies on the group A lactobacilli has resolved whether the antibodies formed on the injection of whole cells are elicited by the wall teichoic acid, the membrane teichoic acid or by both of these substances. Thus the classification of a lactobacillus as belonging to serological group A may depend on the production of antibodies to the membrane teichoic acid and their reaction primarily with the wall component. The definition of the group antigen in this case would therefore depend on whether it is defined as the component eliciting antibody production or the component detected in a particular serological procedure.

Quantitative precipitin tests have shown that teichoic acid from Lactobacillus helveticus cross-reacted with antisera to groups D, E and F lactobacilli and group A streptococci. In the case of the group D reaction, the $L$. helveticus membrane teichoic acid was probably combining with antibodies against the $L$. plantarum membrane glycerol teichoic acid rather than the wall ribitol teichoic acid; studies on the membrane component from one strain of L. plantarum $(=L$. arabinosus $17-5)$ indicated a low degree of $\alpha$-glucosyl substitution (Critchley, Archibald \& Baddiley, 1962). The reaction with group $\mathrm{E}$ antiserum, however, could depend on antibodies against the wall glycerol teichoic acid. This is the group antigen which has been shown in four species to contain glucose substituents (Sharpe et al. 1964) and in one of them (L. buchneri) to be partially substituted with $\alpha$-D-glucosyl residues (Shaw \& Baddiley, I964).

The results with antisera against group $F$ lactobacilli and group A streptococci indicated that glycerol teichoic acids differing in structure may nevertheless crossreact. The teichoic acid from group A streptococci is unsubstituted with sugar (McCarty, 1959) whereas the corresponding product from group F lactobacilli (Lactobacillus fermenti) contains galactose and a disaccharide of glucose and galactose (Wicken \& Knox, 1970).

The reaction of certain antisera against group A streptococci with extracts from various Gram-positive bacteria, including streptococci, staphylococci and sporulating bacilli, was observed by McCarty (1959); polyglycerophosphate was isolated from a group A streptococcus, and it was concluded that this component is widespread amongst Gram-positive bacteria. More recently, Sharpe \& Brock (personal communication) showed that antisera against a strain of Lactobacillus acidophilus reacted with 'almost all of 98 strains of lactobacilli' as well as some other Gram-positive bacteria; glucosyl-glycerol teichoic acid was isolated from one of the reacting strains of $L$. case $i$, and it was suggested that this component was responsible for the serological reactivity of the other strains. Both of these studies implied that a common serological reaction was due to a teichoic acid, the structure of which was similar to that isolated from one particular strain. However, the results of the present study indicate that such a conclusion is not necessarily valid because of the cross-reaction of teichoic acids differing in structure.

With regard to the observations on serological cross-reactions, the situation may be analogous to that discussed by Kabat (1966). McCarty (1964) had noted that certain group A streptococcal antisera reacted equally well with streptococcal glycerol 
teichoic acid whether or not alanine was substituted on carbon 2, and Kabat suggested that such antisera 'would have a specificity complementary to the $-\mathrm{CH}-$ aspect of carbon 2 of the glycerol teichoic acid and not involving the more hydrophilic side of the molecule'. A molecular model of part of an $\alpha$-D-glucosyl-substituted glycerol teichoic acid can be constructed in which all the glucosyl residues project in the same direction, thus fulfilling the requirements for Kabat's proposition. Different antibodies reacting with the teichoic acid could then have specificities depending primarily on the glucosyl substituents (e.g. antiserum 176) or independent of the glucosyl substituents but dependent on the glycerol phosphate 'backbone' (e.g. antiserum I70). An analogous situation has been proposed by Lüderitz, Staub \& Westphal (I966) to account for the serological specificity of the branched chain $\mathrm{O}$-specific polysaccharides of Salmonella.

We wish to thank Miss Merilyn Hewett for assistance, Dr B. A. Stone, University of Melbourne, for a sample of methyl- $\beta$-D-glucoside, and Dr J. K. Pollak, University of Sydney, for making available the C-P-K atomic models. This work was supported by a grant from the National Health and Medical Research Council of Australia.

\section{REFERENCES}

Archibald, A. R., Baddlley, J. \& Heptinstall, S. (1969). The distribution of the glucosyl substituents along the chain of the teichoic acid in walls of Lactobacillus buchneri NCIB 8007. Biochemical Journal III, 245-246.

Archibald, A. R., CoApes, H. E. \& Stafford, G. H. (1969). The action of dilute alkali on bacterial cell walls. Biochemical Journal Ir3, 899-900.

Critchley, P., Archibald, A. R. \& BadDiley, J. (1962). The intracellular teichoic acid from Lactobacillus arabinosus 17-5. Biochemical Journal 85, 420-43I.

Forrester, I. T. \& Wicken, A. J. (I966). The chemical composition of the cell walls of some thermophilic bacilli. Journal of General Microbiology 42, 147-154.

Glaser, L. \& Burger, M. M. (I964). The synthesis of the teichoic acids. III. Glucosylation of polyglycerophosphate. Journal of Biological Chemistry 239, 3187-3191.

HANeS, C. S. \& Isherwood, F. A. (1949). Separation of phosphoric esters on the filter paper chromatogram. Nature, London r64, I $107-1$ I 12.

HewetT, M. J., KNox, K. W. \& WiCKen, A. J. (1970). Studies on the group F antigen of lactobacilli: Detection of antibodies by haemagglutination. Journal of General Microbiology 60, 3I 5-322.

Jeanes, A., WiSe, C. S. \& Dimler, R. J. (195I). Improved techniques in paper chromatography of carbohydrates. Analytical Chemistry 23, 4I5-420.

KABAT, E. A. (I966). The nature of an antigenic determinant. Journal of Immunology 97, I-II.

KNOX, K. W. \& HALL, E. A. (I965). The linkage between the polysaccharide and mucopeptide components of the cell wall of Lactobacillus casei. Biochemical Journal 96, 302-309.

Knox, K. W., HewetT, M. J. \& Wicken, A. J. (1970). Studies on the group F antigen of lactobacilli: Antigenicity and serological specificity of teichoic acid preparations. Journal of General Microbiology 60, 303-314.

Lüderitz, O., Staub, A.-M. \& Westphal, O. (1966). Immunochemistry of O and R antigens of Salmonella and related Enterobacteriaceae. Bacteriological Reviews 30, 193-255.

MCCARTY, M. (1959). The occurrence of polyglycerophosphate as an antigenic component of various Gram-positive bacterial species, Journal of Experimental Medicine ro9, 361-378.

MCCARTY, M. (1964). The role of D-alanine in the serological specificity of group A streptococcal glycerol teichoic acid. Proceedings of the National Academy of Sciences of the United States of America 52, 259-265.

Mills, C. K. (1969). Agglutinating antigens of Lactobacillus jugurti ATCC 521. Journal of General Microbiology 57, 105-I I4. 
SASTRY, P. S. \& KATES, M. (1964). Lipid components of leaves. Biochemistry 3, 1271-1 280.

ShaRpe, M. E. (1955). Serological classification of lactobacilli. Journal of General Microbiology 12, 107-I 22.

Sharpe, M. E., Davison, A. L. \& Baddiley, J. (I964). Teichoic acids and group antigens in lactobacilli. Journal of General Microbiology 34, 333-340.

Shaw, N. \& BADdileY, J. (1964). The teichoic acid from the walls of Lactobacillus buchneri NCIB 8007. Biochemical Journal 93, 317-32I.

WICKEN, A. J. (1966). The glycerol teichoic acid from the cell wall of Bacillus stearothermophilus в 65. Biochemical Journal 99, I08-1 I6.

Wicken, A. J. \& KNOX, K. W. (I970). Studies on the group F antigen of lactobacilli: Isolation of a teichoic acid-lipid complex from Lactobacillus fermenti NCTC699I. Journal of General Microbiology 6o, 293-302. 